\title{
Fluorescent Fe(II) metallo-supramolecular polymers: metal-ion-directed self-assembly of new bisterpyridines containing triethylene glycol chains
}

\author{
Ravindra R Pal ${ }^{1}$, Masayoshi Higuchi ${ }^{1,2}$, Yuichi Negishi ${ }^{3}$, Tatsuya Tsukuda ${ }^{4}$ and Dirk G Kurth ${ }^{5}$ \\ We synthesized new ditopic bisterpyridine (BTPY) ligands (L2 and L4) containing triethylene glycol (TEG) chains at the \\ ortho-position of the peripheral pyridine ring and succeeded in obtaining fluorescent Fe(II) metallo-supramolecular \\ polyelectrolytes (FeL2-MEPE and FeL4-MEPE) through complexation of Fe(II) ions with L2 and L4, respectively. The Fe(II) ion \\ is known to quench fluorescence, but FeL2-MEPE shows a retention of quantum yield that is nearly threefold higher than that \\ of the unsubstituted analog (FeL3-MEPE). We investigated the substituent effects of TEG chains on metallo-supramolecular \\ polymers and their fluorescent and electrochemical properties in detail.
}

Polymer Journal (2010) 42, 336-341; doi:10.1038/pj.2010.3; published online 10 February 2010

Keywords: bisterpyridine; fluorescence; metallo-supramolecular polymers; triethylene glycol

\section{INTRODUCTION}

$\pi$-Conjugated polymers with fluorescent properties have attracted significant attention in the fields of organic light-emitting diodes ${ }^{1}$ and plastic solar cells, ${ }^{2}$ in which, recently, much effort has been devoted to the introduction of metal ions to the backbone to tune photophysical properties by harvesting the triplet state emission. ${ }^{3}$ However, poor processing properties often prevent device application of these polymers. Recently, fluorescent metallo-supramolecular polymers have become of great interest because their properties, such as solubility or viscosity, are controllable by changing the ligands and metal-ion species. In particular, the importance of metallo-supramolecular polyelectrolytes (MEPE) based on bisterpyridine (BTPY) or its derivatives in tuning optoelectronic properties after linking with conjugated molecules has been well recognized. ${ }^{4}$ The optoelectronic properties, which largely depend on the light emission efficiency of fluorescent MEPE, can be tuned by the choice of metal ion and the modification of ligands. Using different metal ions ${ }^{5-7}$ as templates to assemble organic building blocks into polymer chains through coordination to chelating terpyridyl units is an appealing strategy for the construction of photoluminescent materials.

Recently, we revealed the importance of structural modification of BTPY with electron-donating and -accepting groups substituted at the peripheral position in electrochemical properties of the corresponding $\mathrm{Fe}(\mathrm{II})-$, $\mathrm{Co}(\mathrm{II})$ - and $\mathrm{Ru}(\mathrm{II})$-MEPEs and photophysical properties of $\mathrm{Ru}(\mathrm{II})$-MEPEs. After a successful study of the substituent effects of BTPYs with electron-donating methoxy groups for change in the photophysical properties of $\mathrm{Ru}(\mathrm{II})$-MEPEs, we have designed new
BTPY with bulky electron-donating triethylene glycol (TEG) chains to investigate the substituent effects on the photophysical properties of $\mathrm{Fe}(\mathrm{II})$-MEPEs. The $\mathrm{Fe}(\mathrm{II})$ ion generates stable Fe(II)-MEPEs with a well-defined octahedral coordination geometry, but fluorescent $\mathrm{Fe}$ (II)MEPEs have not been reported so far ${ }^{4,8-11}$ to our knowledge; however, it is well known that $\mathrm{Fe}(\mathrm{II})$ ions quench the fluorescence of $\mathrm{Fe}(\mathrm{II})$-MEPEs bearing BTPY ${ }^{9,12}$ or 2,6-bis(1'-methylbenzimidazolyl)pyridine. ${ }^{13}$ Therefore, we chose Fe(II) ions for the study of substituent effects on fluorescent properties in metallo-supramolecular polymers.

The motivation for this study stems from the necessity for new fluorescent materials with insights from a systematic investigation of the structure-property relationship, which is virtually unknown but is highly desirable for the design of new fluorescent functional materials. In the quest to develop new functional materials, we report (1) the synthesis of novel BTPY ligands with TEG chains as flexible substituents at the peripheral pyridines of BTPY, (2) the formation of $\mathrm{Fe}(\mathrm{II})-\mathrm{MEPEs}$ during the complexation of new ligands with $\mathrm{Fe}(\mathrm{II})$ ions, (3) the fluorescent properties of $\mathrm{Fe}(\mathrm{II})$ polymers and (4) the relationship between fluorescent properties and polymer structures.

\section{EXPERIMENTAL PROCEDURE}

Materials and general experimental details

Unless otherwise noted, all reactions were performed under an inert atmosphere of argon using conical glass vials that can be capped with a septum. All chemicals were of reagent grade and used as received, unless otherwise specified. $\mathrm{Fe}(\mathrm{OAc})_{2}$ was purchased from Sigma-Aldrich (St Louis, MO, USA),

${ }^{1}$ International Center for Materials Nanoarchitectonics, National Institute for Materials Science, Tsukuba, Ibaraki, Japan; ${ }^{2}$ PRESTO, Japan Science and Technology Agency, Chiyoda-ku, Tokyo, Japan; ${ }^{3}$ Department of Applied Chemistry, Tokyo University of Science, Shinjuku-ku, Tokyo, Japan; ${ }^{4}$ Catalysis Research Center, Hokkaido University, Kita-ku, Sapporo, Japan and ${ }^{5}$ Technologie der Material Synthese, Universität Würzberg, Rontgenring, Würzberg, Germany

Correspondence: Dr M Higuchi, International Center for Materials Nanoarchitectonics, National Institute of Materials Science, 1-1 Namiki, Tsukuba 305-0044, Japan. E-mail: HIGUCHI.Masayoshi@nims.go.jp

Received 22 July 2009; revised 30 November 2009; accepted 15 December 2009; published online 10 February 2010 
and dehydrated ethanol, methanol, acetic acid and dimethylsulfoxide were purchased from Wako (Osaka, Japan). The spectroscopic grade and fluorescence-grade methanol and $\mathrm{CHCl}_{3}$ were purchased from Kanto Chemical (Tokyo, Japan).

Synthesis of 4'-(4-bromo-phenyl)-6 22-[2-(2-methoxy-ethoxy)ethoxy]-ethox $\}-\left[2,2^{\prime} ; 6^{\prime}, 2^{\prime \prime}\right]$ terpyridine (L1)

Dry hexane $(40 \mathrm{ml})$ was placed into a $200 \mathrm{ml}$ two-neck flask containing $\mathrm{NaH}$ $(0.10 \mathrm{~g}, 4.16 \mathrm{mmol})$ and stirred under a nitrogen gas atmosphere. After $2 \mathrm{~min}$, the hexane was removed and dried under vacuum, followed by the addition of dry tetrahydrofuran $(30 \mathrm{ml})$. A solution of TEG monomethyl ether $(\mathbf{3})(0.30 \mathrm{~g}$, $1.82 \mathrm{mmol})$ in dry tetrahydrofuran $(10 \mathrm{ml})$ was added and the solution was refluxed for $1 \mathrm{~h}$. The solution of 6-bromo-4'-(4-bromo-phenyl)-[2,2'; $\left.; 6^{\prime}, 2^{\prime \prime}\right]$ terpyridine $(1)^{14}(0.75 \mathrm{~g}, 1.62 \mathrm{mmol})$ in dry tetrahydrofuran $(100 \mathrm{ml})$ was added slowly. The reaction mixture was refluxed and the course of the reaction was monitored by thin-layer chromatography. The reaction was quenched with saturated $\mathrm{NH}_{4} \mathrm{Cl}$, followed by extraction and neutralization with $\mathrm{CH}_{3} \mathrm{COOH}$. The solvent was evaporated under vacuum, and the viscous liquid was purified by column chromatography on silica gel using $\left(\mathrm{CH}_{2} \mathrm{Cl}_{2} /\right.$ hexane: $\left.1 / 1\right)$ and $\left(\mathrm{CH}_{2} \mathrm{Cl}_{2} / \mathrm{EtOAc:} 9.5 / 0.5\right)$ as eluents to yield a colorless viscous liquid $\mathrm{L} 1$ $(0.87 \mathrm{~g}, 87 \%)$, which was solidified after cooling. ${ }^{1} \mathrm{H}$ nuclear magnetic resonance (NMR) $\left(300 \mathrm{MHz}, \mathrm{CDCl}_{3}\right) \delta=8.64-8.61\left(\mathrm{~m}, 3 \mathrm{H}, \mathrm{H}_{7,9,15}\right), 8.57(\mathrm{~d}, 1 \mathrm{H}$, $\left.J=1.5 \mathrm{~Hz}, \mathrm{H}_{12}\right), 8.24\left(\mathrm{~d}, 1 \mathrm{H}, J=7.5 \mathrm{~Hz}, \mathrm{H}_{4}\right), 7.84\left(\mathrm{ddd}, 1 \mathrm{H}, J_{1}=J_{2}=7.6 \mathrm{~Hz}\right.$, $\left.J_{3}=1.8 \mathrm{~Hz}, \mathrm{H}_{14}\right), 7.76-7.62\left(\mathrm{~m}, 5 \mathrm{H}, \mathrm{H}_{3}, 17,18\right), 7.35\left(\mathrm{~m}, 1 \mathrm{H}, \mathrm{H}_{13}\right), 6.85(\mathrm{~d}, 1 \mathrm{H}$, $\left.J=8.25 \mathrm{~Hz}, \mathrm{H}_{2}\right), 4.65\left(\mathrm{t}, 2 \mathrm{H}, J=4.38 \mathrm{~Hz}\right.$, tpyOCH$\left._{2}\right), 3.95(\mathrm{t}, 2 \mathrm{H}, J=5.1 \mathrm{~Hz}$, tpyOCH $\left.\mathrm{CH}_{2}\right), 3.79-3.64(\mathrm{~m}, 6 \mathrm{H}$, TEG backbone $), 3.54(\mathrm{t}, 2 \mathrm{H}, J=2.7 \mathrm{~Hz}$, $\left.\mathrm{CH}_{2} \mathrm{OCH}_{3}\right), 3.33\left(\mathrm{~s}, 3 \mathrm{H}, \mathrm{OCH}_{3}\right) ;{ }^{13} \mathrm{C} \mathrm{NMR}\left(75 \mathrm{MHz}, \mathrm{CDCl}_{3}\right) \delta=162.99$, $155.97,155.93,153.17,149.04,148.88,139.37,137.67,136.87,132.12$, $128.80,123.88,123.34,121.34,118.39,118.36,114.17,111.68,71.88,70.67$, $70.63,70.53,69.70,65.02,59.01$; HRMS (LCMS-IT-TOF-MS): found $\mathrm{m} / z$ : $571.965[\mathrm{M}+\mathrm{Na}]^{+} ; \mathrm{C}_{28} \mathrm{H}_{28} \mathrm{NaN}_{3} \mathrm{O}_{4} \mathrm{Br}$ requires 571.960.

\section{General procedure for one-pot synthesis of BTPY}

A diboronic compound ( 4 or $5,0.5$ equiv), $\mathrm{K}_{2} \mathrm{CO}_{3}$ (3.0 equiv) and $\mathrm{PdCl}_{2}\left(\mathrm{PPh}_{3}\right)_{2}$ $(5 \mathrm{~mol} \%)$ were sequentially added to a dimethylsulfoxide solution of monoterpyridine (L1 or $4^{\prime}$-(4-bromo-phenyl)-[2,2';6, $\left.2^{\prime \prime}\right]$ terpyridine (2)). The solution was degassed and stirred at $80-120^{\circ} \mathrm{C}$ under an argon atmosphere. The course of the reaction was monitored by thin-layer chromatography. Catalysts were removed by filtration and washed thoroughly with $\mathrm{CHCl}_{3}$ after the reaction mixture was cooled to room temperature. The solvent was evaporated under vacuum and then precipitated into $\mathrm{H}_{2} \mathrm{O}$. The solid compounds were filtered and washed with $\mathrm{H}_{2} \mathrm{O}$, followed by washing with $\mathrm{MeOH}$. BTPYs L2, L3 and L4 were dried and purified by column chromatography on activated basic alumina $\left(\mathrm{CH}_{2} \mathrm{Cl}_{2}\right.$-EtOAc as eluents), followed by use of a gel permeation chromatography (LC-9104, Recycling Preparative HPLC, Japan Analytical (Tokyo, Japan)) column using $\mathrm{CHCl}_{3}$ as an eluent (yields: 28-38\%).

BTPY L2 $(0.041 \mathrm{~g}, 29 \%)$ is a light-yellow viscous liquid: ${ }^{1} \mathrm{H}$ NMR $(300 \mathrm{MHz}$, $\left.\mathrm{CDCl}_{3}\right) \delta=8.72-8.56\left(\mathrm{~m}, 8 \mathrm{H}, \mathrm{H}_{7,7^{\prime}}, 9,9^{\prime}, 12,12,15,15^{\prime}\right), 8.25\left(\mathrm{~d}, 2 \mathrm{H}, J=7.6 \mathrm{~Hz}, \mathrm{H}_{4,4^{\prime}}\right)$, 7.78-7.69 (ddd, $\left.2 \mathrm{H}, J_{1}=J_{2}=7.8 \mathrm{~Hz}, J_{3}=3.0 \mathrm{~Hz}, \mathrm{H}_{13}, 13^{\prime}\right), 7.67-7.63(\mathrm{~m}, 14 \mathrm{H}$, $\mathrm{H}_{14}, 14^{\prime}, 17,17^{\prime}, 18,18^{\prime}$, tpyAr- $\left.\mathrm{C}_{6} \mathrm{H}_{4^{-}}\right), 7.37-7.34\left(\mathrm{~m}, 2 \mathrm{H}, \mathrm{H}_{3}, 3^{\prime}\right) 6.85(\mathrm{~d}, 2 \mathrm{H}$, $\left.J=8.25 \mathrm{~Hz}, \mathrm{H}_{2}, 2^{\prime}\right), 4.65\left(\mathrm{t}, 2 \mathrm{H}, J=4.8 \mathrm{~Hz}, \operatorname{tpyOCH}_{2}\right), 3.95(\mathrm{t}, 2 \mathrm{H}, J=4.8 \mathrm{~Hz}$, tpyOCH $\left.\mathrm{CH}_{2}\right), 3.79-3.64(\mathrm{~m}, 12 \mathrm{H}$, TEG backbone), $3.54(\mathrm{t}, 4 \mathrm{H}, J=2.7 \mathrm{~Hz}$, $\left.\mathrm{CH}_{2} \mathrm{OCH}_{3}\right), 3.33\left(\mathrm{~s}, 6 \mathrm{H}, \mathrm{OCH}_{3}\right) ;{ }^{13} \mathrm{C} \mathrm{NMR}\left(75 \mathrm{MHz}, \mathrm{CDCl}_{3}\right) \delta=163.03$, $156.22,155.87,153.40,149.56,149.10,141.14,139.62,139.43,137.75,136.91$, $127.77,127.58,123.86,121.40,118.58,114.21,11.65,71.91,70.72,70.68,70.58$, 69.79, 65.09, 59.09; HRMS: found $m / z: 1039.425[\mathrm{M}+\mathrm{Na}]^{+} ; \mathrm{C}_{62} \mathrm{H}_{60} \mathrm{NaN}_{6} \mathrm{O}_{8}$ requires 1039.423 .

BTPY L3 $(0.020 \mathrm{~g}, 38 \%)$ is a light-yellow solid: ${ }^{1} \mathrm{H}$ NMR $\left(300 \mathrm{MHz}, \mathrm{CDCl}_{3}\right)$ $\delta=8.81\left(\mathrm{~d}, 4 \mathrm{H}, \mathrm{H}_{1}, 15\right), 8.76-8.66\left(\mathrm{~m}, 8 \mathrm{H}, \mathrm{H}_{4}, 7,9,12\right), 8.06-7.99$ (ddd, $4 \mathrm{H}$, $\left.J_{1}=J_{2}=9.0 \mathrm{~Hz}, J_{3}=4.0 \mathrm{~Hz}, \mathrm{H}_{3,12}\right), 7.97-7.65\left(\mathrm{~m}, 12 \mathrm{H}, \mathrm{H}_{17}, 18\right.$, TPY-Ph-TPY $)$, 7.45-7.35 (m, $\left.4 \mathrm{H}, \mathrm{H}_{2,14}\right) ;{ }^{13} \mathrm{C}$ NMR $\left(75 \mathrm{MHz}, \mathrm{CDCl}_{3}\right) \delta=156.4,156.1,149.7$, $149.25,141.3,137.8,136.9,128.1,128.0,124.02,121.6$; MALDI-MS (\%): calculated $\mathrm{m} / z: 692.27$, observed $\mathrm{m} / z: 692.4$ (100).

BTPY L4 $(0.020 \mathrm{~g}, 38 \%)$ is a light-yellow viscous liquid: ${ }^{1} \mathrm{H}$ NMR $(300 \mathrm{MHz}$, $\left.\mathrm{CDCl}_{3}\right) \delta=8.75-8.66\left(\mathrm{~m}, 8 \mathrm{H}, \mathrm{H}_{7,9,12,15}\right), 8.27\left(\mathrm{~d}, 2 \mathrm{H}, J=7.2 \mathrm{~Hz}, \mathrm{H}_{4}\right), 7.99-7.73$ $\left(\mathrm{m}, 12 \mathrm{H}, \mathrm{H}_{3}, 13,17,18\right), 7.26\left(\mathrm{~m}, 2 \mathrm{H}, \mathrm{H}_{14}\right) 6.85\left(\mathrm{~d}, 2 \mathrm{H}, J=8.25 \mathrm{~Hz}, \mathrm{H}_{2}\right), 4.68$ (t, $4 \mathrm{H}, J=6.0 \mathrm{~Hz}$, tpyOCH$\left.)_{2}\right), 3.95\left(\mathrm{t}, 4 \mathrm{H}, J=4.2 \mathrm{~Hz}\right.$, tpyOCH$\left._{2} \mathrm{CH}_{2}\right), 3.77-3.64$ (m, 12H, TEG backbone), $3.54\left(\mathrm{t}, 4 \mathrm{H}, J=6.0 \mathrm{~Hz}, \mathrm{CH}_{2} \mathrm{OCH}_{3}\right), 3.34(\mathrm{~s}, 6 \mathrm{H}$, $\left.\mathrm{OCH}_{3}\right) ;{ }^{13} \mathrm{C}$ NMR $\left(75 \mathrm{MHz}, \mathrm{CDCl}_{3}\right) \quad \delta=163.06,156.25,155.93,153.43$, $149.57,149.12,140.98,139.43,138.02,136.92,127.83,123.87,121.42,118.63$, 114.22, 111.68; HRMS: found $m / z: 963.405[\mathrm{M}+\mathrm{Na}]^{+} ; \mathrm{C}_{56} \mathrm{H}_{56} \mathrm{NaN}_{6} \mathrm{O}_{8}$ requires 963.407.

\section{General procedure for the preparation of $\mathrm{Fe}(\mathrm{II})$-based MEPEs (FeL2-MEPE, FeL3-MEPE and FeL4-MEPE)}

Equimolar amounts of the ligand and $\mathrm{Fe}(\mathrm{OAc})_{2}$ were refluxed in argonsaturated $\mathrm{CH}_{3} \mathrm{COOH}$ ( $\sim 5 \mathrm{ml}$ solvent per $\mathrm{mg}$ of ligand) for $24 \mathrm{~h}$. The reaction solution was cooled to room temperature and filtered to remove a small amount of insoluble residue. The filtrate was moved to a Petri dish, and the solvent was evaporated slowly to dryness. The brittle film was collected and dried further in vacuum overnight to yield the corresponding Fe(II)-MEPEs $(>92 \%)$.

\section{RESULTS AND DISCUSSION}

We have designed and synthesized a new TPY ligand (L1) containing a TEG chain at the ortho-position of the peripheral pyridine ring of 6-bromo-4'-(4-bromo-phenyl)- $\left[2,2^{\prime} ; 6^{\prime}, 2^{\prime \prime}\right]$ terpyridine $(1)^{14}$ in good chemical yield by means of chemoselective nucleophilic substitution (Scheme 1). ${ }^{15}$ Only one peripheral pyridine ring of TPY was substituted to prevent steric crowding in the coordination sphere. The synthon of L1 opens the door for the synthesis of new BTPY ligands, L2 and L4, using one-pot Suzuki-type dimerization of mono-terpyridines. For comparative study of the properties of MEPEs, L3 without TEG chains is also synthesized, using the above methodology, from $4^{\prime}$-(4-bromo-phenyl)- $\left[2,2^{\prime} ; 6^{\prime}, 2^{\prime \prime}\right]$ terpyridine (2). ${ }^{14}$ All of the ligands, L1-L4, were purified by alumina column chromatography, followed by preparative gel permeation chromatography, and were characterized by NMR and mass spectroscopy techniques.

Metal-ion-induced self-assembly of BTPYs was carried out by refluxing equimolar amounts of the ligand and $\mathrm{Fe}(\mathrm{OAc})_{2}$ in acetic acid under an argon atmosphere, followed by slow evaporation of the solvent and drying in vacuum. The color of the solution turns purple during complexation, indicating the formation of the corresponding $\mathrm{Fe}(\mathrm{II})$-MEPEs (Figure 1).

Ultraviolet-visible and fluorescent spectra of ligands (L2, L3 and L4) and the corresponding Fe(II)-MEPEs are shown in Figure 2, and the data are summarized in Table 1. Ultraviolet-visible spectra of the ligands show a red shift up to $12 \mathrm{~nm}$ when the spacer length from two phenylene ( $\mathrm{L} 4, \lambda=308 \mathrm{~nm}$ ) to three phenylene units (L2, $\lambda=320 \mathrm{~nm}$ ) changes, owing to the elongation of the $\pi$-conjugation along the chains. Absorption spectra show a change with an increase in $\varepsilon_{\max }$ of these ligands from two to three phenylene units, which is ascribable to intraligand ligand-centered transitions. In contrast, Fe(II)-MEPEs (FeL2-MEPE, $\lambda=571 \mathrm{~nm}$; and FeL4-MEPE, $\lambda=570 \mathrm{~nm}$ ) show an almost constant metal-to-ligand charge transfer (MLCT) band, except for an increase in $\varepsilon_{\max }$, when the spacer increases from two to three phenylene groups, attributed possibly to the decoupling of the two terpyridine moieties by interposed phenylene units. However, the introduction of flexible, electron-donating TEG units at the peripheral position of BTPY (L2) shows an increase in $\varepsilon_{\max }$, compared with normal BTPY (L3). Similarly, their corresponding Fe(II)-MEPEs show a change in $\varepsilon_{\max }$, except to the MLCT band. The obtained results clearly follow the reported result, ${ }^{16}$ which deals with the effects of electron-rich and electron-deficient groups on the absorption properties.

The photoluminescence properties of ligands and $\mathrm{Fe}(\mathrm{II})$-MEPEs are summarized in Table 1. A strong excitation band for ligands L2 $(\lambda=337 \mathrm{~nm})$ and $\mathrm{L} 3(\lambda=338 \mathrm{~nm})$ was observed when they were excited 

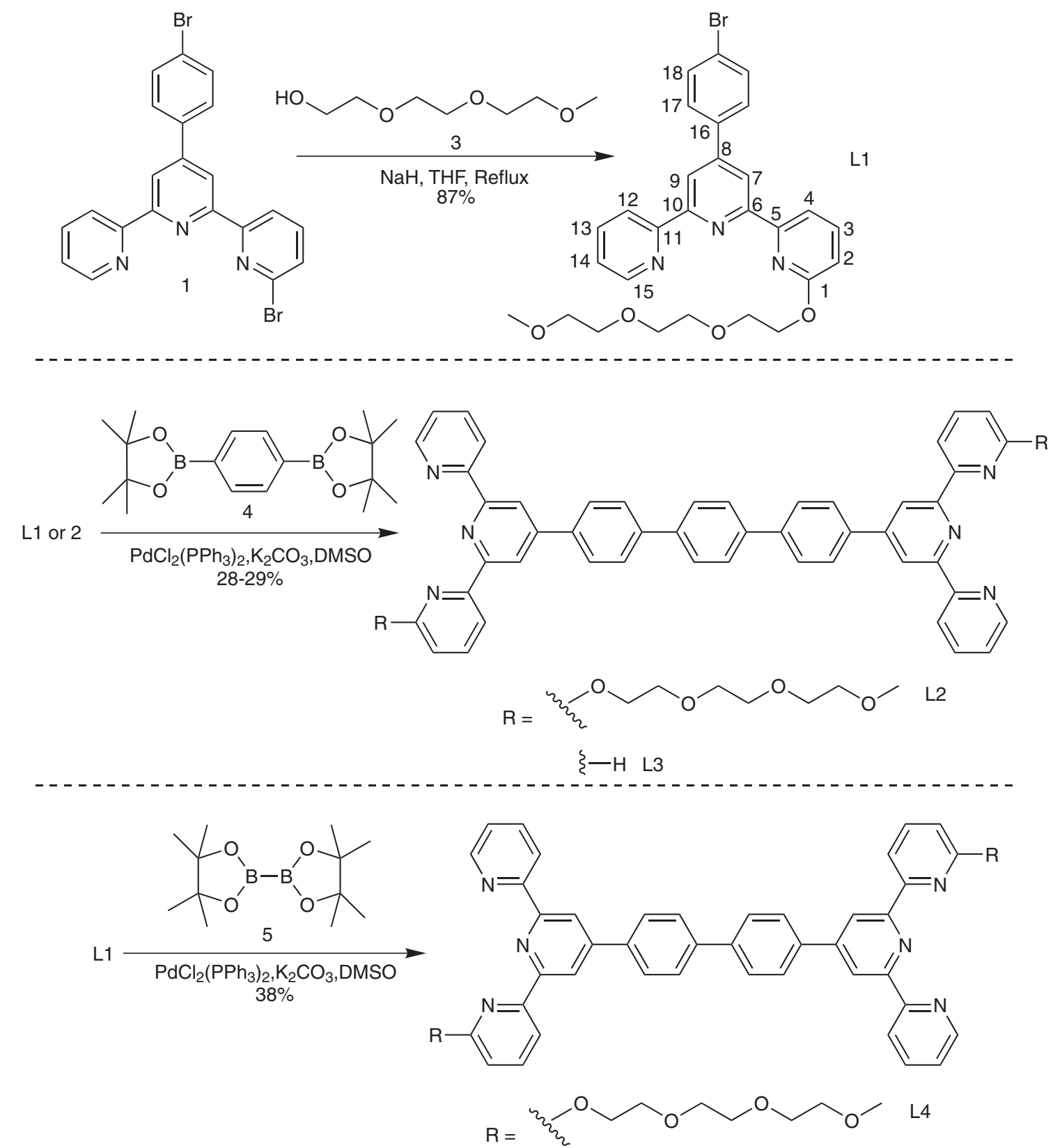

Scheme 1 Synthesis of L1-L4.

at their corresponding emission band. Ligands $\mathrm{L} 2(\lambda=387 \mathrm{~nm})$ and L3 $(\lambda=384 \mathrm{~nm})$ show a broad photoluminescence peak, whereas ligand L4 shows sharp excitation $(\lambda=325 \mathrm{~nm})$ and emission $(\lambda=371 \mathrm{~nm})$ bands. Ligand L2 shows the highest absolute fluorescence quantum yield $\left(\Phi_{\mathrm{abs}}=0.82\right)$, compared with ligands L3 $\left(\Phi_{\mathrm{abs}}=0.78\right)$ and L4 $\left(\Phi_{\mathrm{abs}}=0.68\right)$. The increase in quantum yield is caused by both extended conjugation of the spacer and the electron-donating effect of TEG chains at the ortho-position of the ligand. Ligands L2 and L3 show a dark blue luminescence color, whereas ligand L4 is colorless at the $365 \mathrm{~nm}$ excitation. In addition, the resultant Fe(II)-MEPEs, FeL2MEPE (bright green), FeL3-MEPE (dark green) and FeL4-MEPE (blue), show a change in emission color with respect to substituents and the length of the spacer (Figure 1). The emission spectra of FeL2MEPE and FeL3-MEPE show a band at 489 and $500 \mathrm{~nm}$, respectively (Figure 2b). However, the emission band of FeL4-MEPE, which has one less phenylene unit as spacer, seems to be at a shorter wavelength $(443 \mathrm{~nm})$ than those of FeL2-MEPE and FeL3-MEPE. The difference in wavelength is caused by the difference in the length of $\pi$-conjugation. Moreover, in the emission spectra of FeL2-MEPE and FeL3MEPE, a shoulder band at $600 \mathrm{~nm}$ is observed, which can be assigned as an emission band arising from the excitation of the MLCT of the polymers. However, in the emission spectrum of FeL4-MEPE, such a shoulder band does not exist because of weak MLCT absorption of the polymer. Interestingly, we observed that FeL4-MEPE shows the highest absolute quantum yield $\left(\Phi_{\mathrm{abs}}=0.22\right)$, compared with FeL2-MEPE $\left(\Phi_{\mathrm{abs}}=0.11\right)$. FeL3-MEPE shows the highest quenching of photoluminescence properties and an absolute quantum yield of just $4 \%$ $\left(\Phi_{\mathrm{abs}}=0.04\right)$, which is nearly threefold less than that of the substituted TEG chain-based FeL2-MEPE. The observed result for FeL3-MEPE is similar to the reported results ${ }^{12,13}$ for $\mathrm{Fe}$ (II) quenching, which only 
a<smiles>[R]c1cccc(-c2cc(-c3ccc(-c4cccc(-c5cccc(C(C)(C)c6ccc(-c7cc(-c8ccccn8)nc(-c8ccccn8)c7)cc6)c5)c4)cc3)cc(-c3ccccn3)n2)n1</smiles>

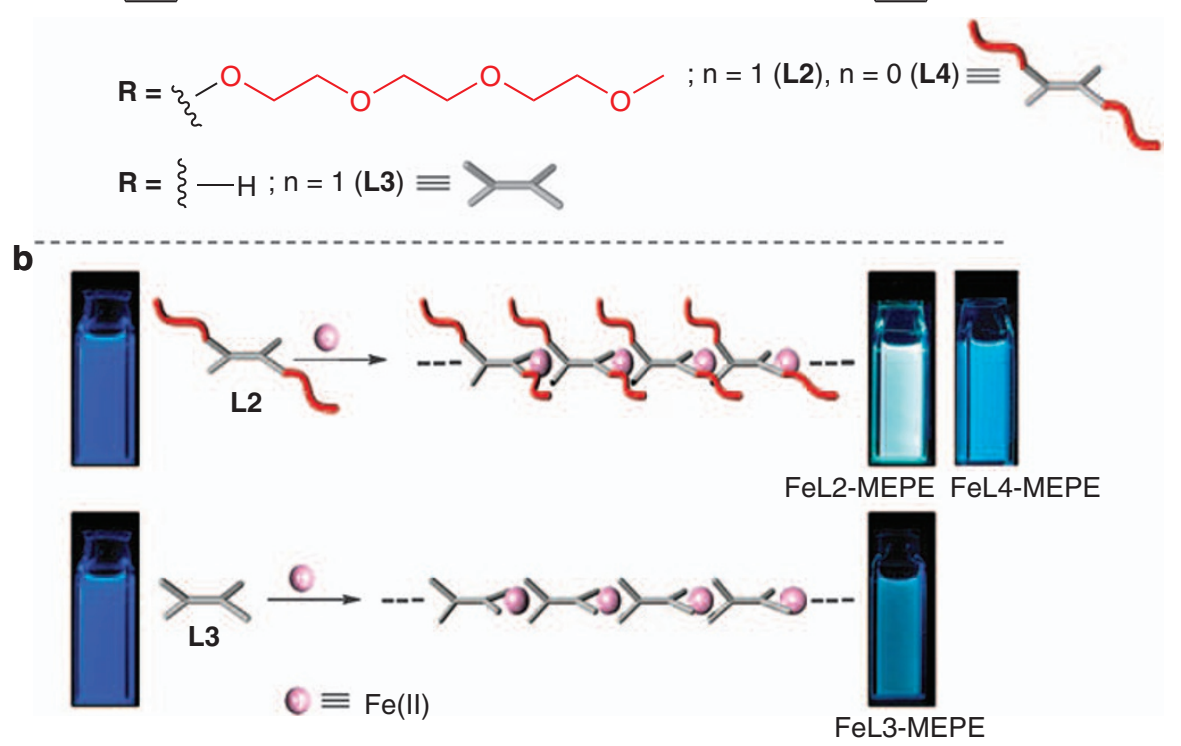

Figure 1 The structures of (a) bisterpyridine ligands (L2, L3 and L4) and (b) the corresponding Fe(II)-MEPEs (FeL2-MEPE, FeL3-MEPE and FeL4-MEPE) and the pictures of fluorescence in each compound.
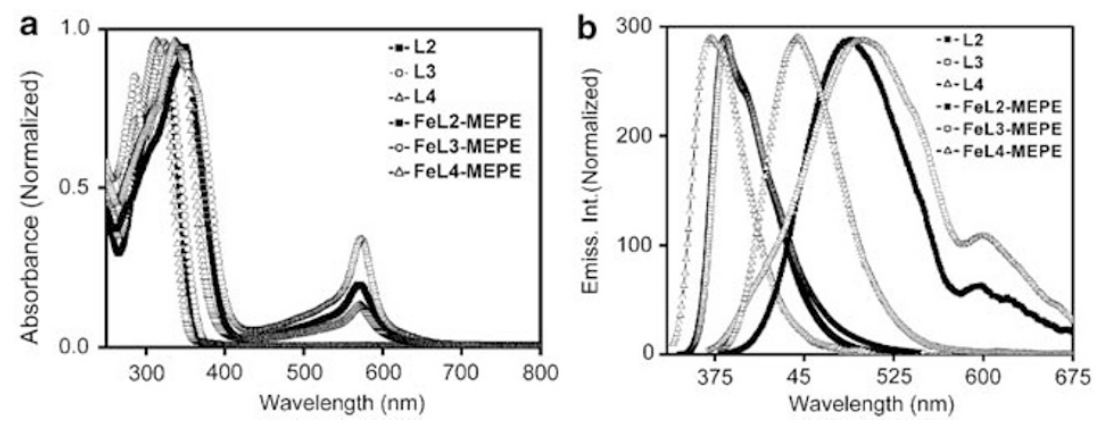

Figure 2 (a) Absorption and (b) emission spectra of ligands (L2, L3 and L4; $c=1 \times 10^{-5} \mathrm{M}, \quad l=10 \mathrm{~mm}$ ) and Fe(II)-MEPEs (FeL2-MEPE, FeL3-MEPE and FeL4-MEPE; $c=1.5 \times 10^{-5} \mathrm{M}, l=10 \mathrm{~mm}$ ) in dichloromethane and methanol solvents, respectively.

describes the spacer modifications at the 4-position of TPY. The enhancement of emission in FeL2-MEPE and FeL4-MEPE may be caused by the charge transfer occurring within the monomer between the electron-rich TEG chain and the metal-coordinated, electrondeficient BTPY moiety, ${ }^{17}$ but the possibility of shielding ${ }^{18}$ fluorescent MEPEs with ortho-position-substituted TEG chains cannot be ruled out and may be responsible for the resultant properties.

To understand emission properties in depth, decay profiles of the luminescence properties of ligands and Fe(II)-MEPEs were measured by the time-correlated single-photon counting technique, using a picosecond diode as the exciter. The unsubstituted ligand L3 shows a longer lifetime $(\tau=0.9 \mathrm{~ns})$ than the corresponding substituted ligands L2 ( $\tau=0.7 \mathrm{~ns}$ ) and L4 ( $\tau=0.8 \mathrm{~ns})$. Possibly, a substituent at the peripheral position of the pyridine ring prohibits effective $\pi$-conjugation of the aromatic rings of the free ligand. ${ }^{19}$ FeL3-MEPE shows the longest lifetime ( $\tau=2.9 \mathrm{~ns})$, compared with FeL2-MEPE $(\tau=2.3 \mathrm{~ns})$ and FeL4-MEPE $(\tau=2.2 \mathrm{~ns})$, and is demonstrated in Table 1 and Figure 3. These results are in good agreement with our recently reported results ${ }^{17}$ that reveal that Fe(II)-MEPEs modified by either electron-donating or -accepting groups show shorter lifetimes than unsubstituted Fe(II)-MEPEs. Moreover, there was a lesser effect of the spacer unit on lifetime.

We further investigated the effect of the concentration of $\mathrm{Fe}(\mathrm{II})$ MEPE and the solvent on fluorescent properties. Figure 4a shows the 
Table 1 Photophysical properties of BTPYs and Fe(II)-MEPEs

\begin{tabular}{|c|c|c|c|c|c|c|}
\hline Entries & $\begin{array}{c}\pi-\pi^{*}, \lambda_{\max }(n m) \\
\left(\varepsilon_{\max }\left(M^{-1} c m^{-1}\right)\right)^{\mathrm{a}}\end{array}$ & $\begin{array}{c}M L C T, \lambda_{\max }(n m) ; \\
\left(\varepsilon_{\max }\left(M^{-1} \mathrm{Cm}^{-1}\right)\right)^{\mathrm{b}}\end{array}$ & $\begin{array}{l}\text { PL, exci., } \\
\lambda_{\max }(n m)\end{array}$ & $\begin{array}{l}\text { PL, emis., } \\
\lambda_{\max }(n m)^{\mathrm{c}}\end{array}$ & $\Phi^{\mathrm{d}}$ & $\tau(n s)^{e}$ \\
\hline L2 & $320(83500)$ & - & 337 & 383 & $0.82(1.62)^{f}$ & 0.7 \\
\hline L4 & $308(78300)$ & - & 325 & 371 & 0.68 & 0.8 \\
\hline FeL2-MEPE & $350(55400)$ & $571(10800)$ & 321,380 & 489 & $0.11\left(6.4 \times 10^{-4}\right)^{g}$ & 2.3 \\
\hline FeL3-MEPE & 335 (27 100) & $573(10700)$ & 351 & 500 & $0.04\left(3.6 \times 10^{-4}\right)^{g}$ & 2.9 \\
\hline
\end{tabular}

Abbreviations: BTPY, bisterpyridine; MEPE, metallo-supramolecular polyelectrolyte.

aThe $\varepsilon_{\max }$ were calculated from $\lambda_{\max }$ for BTPY $\left(c=1.0 \times 10^{-5} \mathrm{M}, l=1 \mathrm{~cm}\right)$ in chloroform solvent.

bThe $\varepsilon_{\max }$ were calculated from $\lambda_{\max }$ for MEPE $\left(1.5 \times 10^{-5} \mathrm{M}, l=1 \mathrm{~cm}\right)$ in methanol solvent

'The concentration of BTPY $\left(c=1.0 \times 10^{-5} \mathrm{M}, I=1 \mathrm{~cm}, \mathrm{~L} 2_{\mathrm{ex}}=335 \mathrm{~nm}, \mathrm{~L} 3_{\mathrm{ex}}=340 \mathrm{~nm}\right.$ and $\left.\mathrm{L}_{\mathrm{ex}}=330 \mathrm{~nm}\right)$ in chloroform solvent and MEPE $\left(c=1.5 \times 10^{-5} \mathrm{M}, l=1 \mathrm{~cm}, \mathrm{FeL} 2-\mathrm{MEPE} \mathrm{ex}_{2}=380 \mathrm{~nm}\right.$,

FeL3-MEPE $_{\mathrm{ex}}=350 \mathrm{~nm}$ and FeL4-MEPE $\left.\mathrm{ex}_{\mathrm{ex}}=330 \mathrm{~nm}\right)$ in methanol solvent, respectively.

${ }^{\mathrm{d}}$ The absolute PL quantum yield determined by Hamamatsu C9920-02 instrument (Hamamatsu Photonics, Hamamatsu, Japan) using chloroform solution of BTPY ( $c=3.5 \times 10^{-5} \mathrm{M}, l=1 \mathrm{~cm}$, and $\left.\lambda_{\mathrm{ex}}=337\right)$ and methanol solution of MEPE $\left(c=3.5 \times 10^{-5} \mathrm{M}, l=1 \mathrm{~cm}\right.$ and $\left.\lambda_{\mathrm{ex}}=375 \mathrm{~nm}\right)$.

eLifetime of BTPY $\left(c=3.5 \times 10^{-5} \mathrm{M}, l=1 \mathrm{~cm}\right.$ and $\left.\lambda_{\mathrm{ex}}=337 \mathrm{~nm}\right)$ on Hamamatsu C4780 instrument and MEPE $\left(c=3.5 \times 10^{-5} \mathrm{M}, l=1 \mathrm{~cm}, \lambda_{\mathrm{ex}}=371 \mathrm{~nm}\right)$ on Hamamatsu C4334 instrument were determined.

${ }^{\mathrm{f}}$ Anthracene in ethanol solution used as a reference for determination of PL quantum yield.

gLaser dye LDS750 $\left(\Phi_{\mathrm{em}}=4 \times 10^{-3}\right)$.

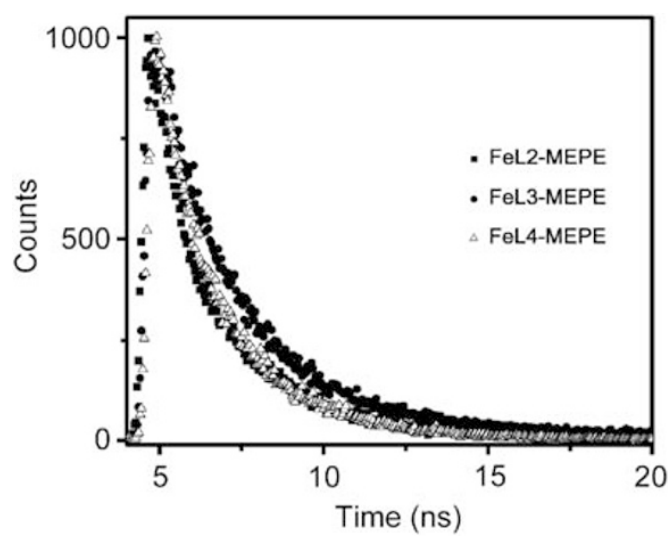

Figure 3 Transient photoluminescence decay curve of Fe(II)-MEPEs (FeL2MEPE, FeL3-MEPE and FeL4-MEPE) in methanol on excitation at $371 \mathrm{~nm}$ $\left(c=3.5 \times 10^{-5} \mathrm{M}, l=10 \mathrm{~mm}\right)$.

change in emission intensity with an increase in concentration of FeL2-MEPE $\left(c=0.1-10.0 \times 10^{-5} \mathrm{M}\right)$. Emission intensity increases up to $3.5 \times 10^{-5} \mathrm{M}$, and thereafter it gradually decreases with increasing concentration. The quantum yield also decreased from 0.11 to 0.02 (with respect to anthracene in ethanol solvent) when the concentration changed from $3.5 \times 10^{-5}$ to $10 \times 10^{-5} \mathrm{M}$. The insets of Figure $4 \mathrm{a}$ show a linear increase in MLCT band with respect to increase in concentration.

The fluorescent properties of FeL2-MEPE show a change in different solvents (Figure 4b). FeL2-MEPE shows a high emission intensity in pure methanol, compared with an acetic acid-methanol (9:1) mixture. However, the fluorescence is completely quenched in a water-methanol (9:1) mixture. These results are in good agreement with previously reported results that deal with the quenching of fluorescence in water or acidic media. ${ }^{9,20}$ Interestingly, in ethylene glycol, FeL2-MEPE shows a twofold increase in emission intensity, compared with pure methanol. We also measured the absorption spectra to confirm the existence of FeL2-MEPE in these solvents by comparing their MLCT absorption (Figure $4 \mathrm{~b}$, inset). The obtained result is in good agreement with reported results, which explains that viscosity is an important parameter for fluorescent enhancement
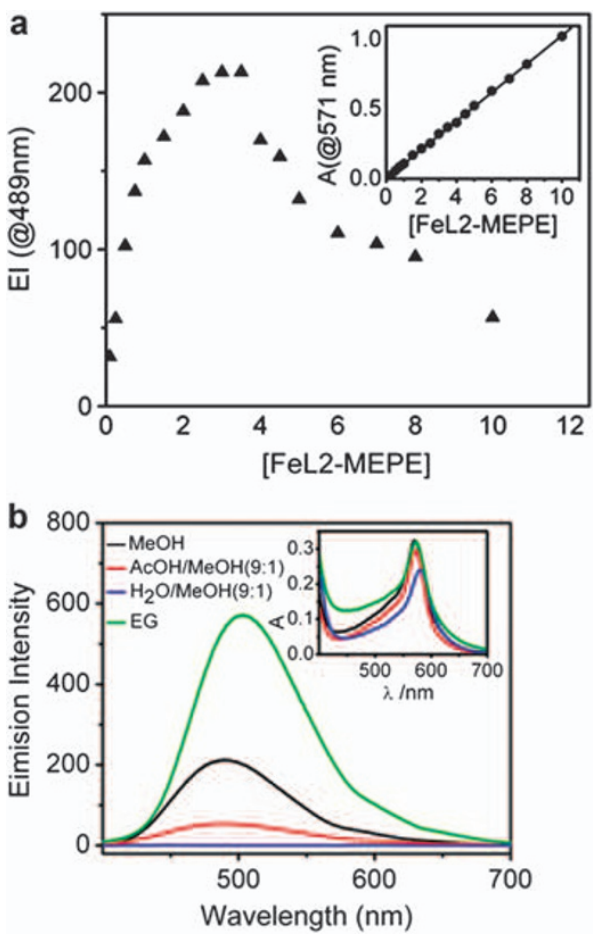

Figure 4 (a) Change in emission intensity with respect to the concentration of FeL2-MEPE $\left(c=0.1-10 \times 10^{-5} \mathrm{M}\right)$ in methanol solvent, and (b) emission spectra of FeL2-MEPE in different solvents $\left(c=3.5 \times 10^{-5} \mathrm{M}\right)$. The inset (a) shows the relationship between absorbance in the MLCT band $(\lambda=571 \mathrm{~nm})$ and concentration, and (b) absorbance in the MLCT band in different organic solvents.

because of the increased solubility of the compound. ${ }^{20}$ In addition to this, the possibility of an interaction between TEG chains and the ethylene glycol solvent cannot be ruled out as a possible cause of the enhancement of fluorescent properties.

The molecular weights and electrochemical properties of $\mathrm{Fe}(\mathrm{II})$ MEPEs are summarized in Table 2. The molecular weights of Fe(II)MEPEs are determined by the SEC-viscometry-RALLs method. The high-molecular weight of $\mathrm{Fe}$ (II)-MEPEs shows the complex formation of TPY units with an Fe(II) ion, even though the TPY units have bulky 
Table 2 Molecular weight and electro-chemical properties of Fe(II)-MEPEs

\begin{tabular}{lcccc}
\hline Entries & $M_{w}{ }^{\mathrm{a}}$ & $E_{\text {oxid. }}(\mathrm{V})^{\mathrm{b}}\left(E_{1 / 2}(\mathrm{~V})\right)^{\mathrm{c}}$ & $\begin{array}{c}\text { HOMO } \\
(\mathrm{eV})^{\mathrm{d}}\end{array}$ & $\begin{array}{c}\text { Band gap } \\
(\mathrm{eV})^{\mathrm{e}}\end{array}$ \\
\hline FeL2-MEPE & $1.6 \times 10^{5}$ & $0.75(0.68)$ & 1.02 & 2.17 \\
FeL3-MEPE & $2.0 \times 10^{5}$ & $0.79(0.75)$ & 1.06 & 2.16 \\
FeL4-MEPE & $1.2 \times 10^{5}$ & $0.73(0.67)$ & 1.00 & 2.17
\end{tabular}

Abbreviation: MEPE, metallo-supramolecular polyelectrolyte.

aThe average molecular weights were determined by SEC-viscometry-RALLS method on Viscotek 270 Dual Detector instrument (Asahi-techneion, Tokyo, Japan) using polyethylene glycol as standard using polymer concentration of $1.5 \mathrm{mg} \mathrm{ml}^{-1}$ in methanol solvent.

${ }^{b}$ Cyclic voltammograms (CV) recorded from thin film coated on glassy carbon electrode in an electrolyte solution of $n-\mathrm{Bu}_{4} \mathrm{NClO}_{4}(0.10 \mathrm{M})$ using a platinum wire as counter electrode, and

$\mathrm{Ag} / \mathrm{AgCl}$ electrode as reference electrode in acetonitrile at room temperature with a scan rate of $100 \mathrm{mV}$; the redox potential for FeL2-MEPE and FeL4-MEPE was determined by using coating of film on glassy carbon electrode with $5 \%$ Nafion solution.

${ }^{c} E_{1 / 2}=0.5\left(E_{\mathrm{pa}}+E_{\mathrm{pc}}\right)$, where $E_{\mathrm{pa}}$ and $E_{\mathrm{pc}}$ are anodic and cathodic peak potentials.

$\mathrm{HOMO}$ level was calculated from oxidation potential versus ferrocene/ferrocinium couple in acetonitrile solution.

eThe band gap was estimated from absorption spectrum in methanol solution by extrapolating the $\lambda_{\max }$ of MLCT peak.

TEG chains at the ortho-position of the peripheral pyridine ring. The electrochemical properties of ligands and Fe(II)-MEPEs were investigated by cyclic voltammetry. No redox peaks are observed for ligands, but $\mathrm{Fe}(\mathrm{II})$-MEPEs show a reversible wave based on the redox between $\mathrm{Fe}(\mathrm{II})$ and $\mathrm{Fe}(\mathrm{III})$. The redox potential $\left(E_{1 / 2}\right), \mathrm{HOMO}$ and band gap of $\mathrm{Fe}(\mathrm{II})$-MEPEs are summarized in Table 2. FeL2-MEPE and FeL4MEPE, the ligands of which are modified by electron-donating TEG chains, display a redox potential at $\sim 0.74 \mathrm{~V}$, about $50 \mathrm{mV}$ more negative than the unsubstituted FeL3-MEPE. By contrast, no significant effect is observed by varying the spacer, as a comparison between FeL2-MEPE and FeL4-MEPE. These results are in good agreement with previously reported results. ${ }^{14}$ In addition, the introduction of substituted TEG chain into BTPY ligands does not have a significant effect on the band gap of their corresponding MEPEs.

\section{CONCLUSION}

Novel fluorescent Fe(II)-MEPEs were synthesized through complexation of $\mathrm{Fe}(\mathrm{II})$ ions with new BTPYS containing flexible TEG chains at the ortho-position of peripheral pyridine rings. The introduction of TEG chains to the ligand resulted in an enhancement of fluorescence of the corresponding polymers: FeL2-MEPE with TEG chains retains nearly threefold higher fluorescence quantum yield than FeL3-MEPE without TEG chains. As a proof of principle, we have studied their photophysical and electrochemical properties, taking into account the effect of the substituent at the peripheral pyridine unit and the length of the spacer. This study confirms that the controlled design of ligands may help to modulate the optoelectronic properties of a given chromosphere through metallo-supramolecular polymerization.

\section{ACKNOWLEDGEMENTS}

This study was financially supported by the Ministry of Education, Culture, Sports, Sciences and Technology (MEXT), Japan.

1 Friend, R. H., Gymer, R. W., Holmes, A. B., Burroughes, J. H., Marks, R. N., Taliani, C., Bradley, D. D. C., Dos Santos, D. A., Brédas, J. L., Lögdlund, M. \& Salaneck, W. R. Electroluminescence in conjugated polymers. Nature 397, 121-128 (1999).

2 Brabec, C. J., Sariciftci, N. S. \& Hummelen, J. C. Plastic solar cells. Adv. Funct. Mater. $11,15-26$ (2001).

3 Wilson, J. S., Dhoot, A. S., Seeley, A.J.A.B., Khan, M. S., Köhler, A. \& Friend, R. H. Spindependent exciton formation in $\pi$-conjugated compounds. Nature 413, 828-831 (2001).

4 Schubert, U. S., Hofmeier, H. \& Newkome, G. R. Modern Terpyridine Chemistry, WileyVCH: Weinheim, (2006).

5 Auffrant, A., Barbieri, A., Barigelletti, F., Collin, J. P., Flamigni, L., Sabatini, C. \& Sauvage, J. P. Dinuclear Iridium(iii) complexes consisting of back-to-back tpy bridging ligands $(n=0,1$, or 2 ) and terminal cyclometallating tridentate $\mathrm{N}-\mathrm{C}-\mathrm{N}$ ligands. Inorg. Chem. 45, 10990-10997 (2006).

6 Medlycott, E. A. \& Hanan, G. S. Designing tridentate ligands for ruthenium(II) with prolonged room temperature luminescence lifetimes. Chem. Soc. Rev. 34, 133-142 (2005).

7 Brombosz, S. M., Zucchero, A. J., Phillips, R. L., Vazquez, D., Wilson, A. \& Bunz, U. H. F. Terpyridine-based Cruciform- $\mathrm{Zn}^{2+}$ complexes as anion-responsive fluorophores. Org. Lett. 9, 4519-4522 (2007) and references therein.

8 Hofmeier, H. \& Schubert, U. S. Recent development of supramolecular chemistry of terpyridine-metal complexes. Chem. Soc. Rev. 33, 373-399 (2004).

9 Dobrawa, R., Lysetska, M., Ballester, P., Grüne, M. \& Würthner, F. Fluorescent supramolecular polymers: metal directed self-assembly of perylene bisimide building blocks. Macromolecules 38, 1315-1325 (2005).

10 Burnworth, M., Mendez, J. D., Schroeter, M., Rowan, S. J. \& Weder, C. Decoupling optical properties in metallo-supramolecular Poly( $p$-phenylene ethynylene)s. Macromolecules 41, 2157-2163 (2008).

11 Hwang, S. H., Moorefield, C. N., Fronzek, R., Lukoyanova, O., Echegoyen, L. \& Newkome, G. R. Construction of triangular metallomacrocycles: $\left[\mathrm{M}_{3}(1,2\right.$ bis(2,2': $6^{\prime}, 2^{\prime}$-terpyridin-4yl-ethynyl) benzene) $\left.{ }_{3}\right][\mathrm{M}=\mathrm{Ru}$ (II), $\mathrm{Fe}(\mathrm{II}), 2 \mathrm{Ru}(\mathrm{II}) \mathrm{Fe}(\mathrm{II})]$. Chem. Commun. 6, 713-715 (2005).

12 Dobrawa, R. \& Würthner, F. Photoluminescent supramolecular polymers: metal-ion directed polymerization of terpyridine-functionalized perylene bisimide dyes. Chem. Commun. 17, 1878-1879 (2002).

13 Knapton, D., Rowan, S. J. \& Weder, C. Synthesis and properties of metallo-supramolecular Poly(p-phenylene ethynylene)s. Macromolecules 39, 651-657 (2006) and references cited therein.

14 Han, F. S., Higuchi, M. \& Kurth, D. G. Metallosupramolecular polyelectrolytes selfassembled from various pyridine ring-substituted bisterpyridines and metal ions: photophysical, electrochemical, and electrochromic properties. J. Am. Chem. Soc. 130, 2073-2081 (2008).

15 Pal, R. R., Higuchi, M. \& Kurth, D. G. Optically active metallo-supramolecular polymers derived from chiral bis-terpyridines. Org. Lett. 11, 3562-3565 (2009).

16 Maestri, M., Armaroli, N., Balzani, V., Constable, E. C. \& Thompson, A.M.W.C. Complexes of the ruthenium (II)- $2,2^{\prime}: 6^{\prime}, 2^{\prime \prime}$-terpyridine family. effect of electronaccepting and-donating substituents on the photophysical and electrochemical properties. Inorg. Chem. 34, 2759-2767 (1995).

17 Han, F. S., Higuchi, M., Ikeda, T., Negishi, Y., Tsukuda, T. \& Kurth, D. G. Luminescence properties of metallo-supramolecular coordination polymers assembled from pyridine ring functionalized Ditopic Bis-terpyridines and Ru(II) Ion. J. Mater. Chem. 18, 4555-4560 (2008).

18 Gosh, P., Bharadwaj, P. K., Roy, J. \& Ghosh, S. Transition metal (II)/(III), Eu(III), and Tb(III) ions induced molecular photonic or gates using trianthryl cryptands of varying cavity dimension. J. Am. Chem. Soc. 119, 11903-11909 (1997) and references cited therein.

19 Yu, S. C., Kwok, C. C., Chan, W. K. \& Che, C. M. Self-assembled electroluminescent polymers derived from terpyridine-based moieties. Adv. Mater. 15, 1643-1647 (2003).

20 Vasquez, J. M., Vu, A., Schultz, J. S. \& Vullev, V. I. Fluorescence enhancement of warfarin induced by interaction with $\beta$-cyclodextrin. Biotechnol. Prog. 25, 906-914 (2009). 